\title{
Evolución de los marcadores serológicos del virus linfotrópico HTLV-I-II, en los bancos de sangre
}

\author{
José Fuentes, Manuel Leiva, Doris Alvarado \\ Instituto de Investigaciones Clínicas, Facultad de Medicina, UNMSM
}

Objetivos: Evaluar el comportamiento de seroprevalencia del virus linfotrópico humano, en Lima, a fin de proponer la utilización de leucorreducción en componentes sanguíneos.

Diseño: Estudio retrospectivo, aleatorio y transversal.

Institución: Instituto de Investigaciones Clínicas, Facultad de Medicina, UNMSM.

Participantes: Bancos de Sangre.

Intervenciones: Se consideró al Banco de Sangre del Hospital Dos de Mayo, con un total de 45041 donantes, de un total de 60 705, de enero de 2002 a octubre de 2011. La población estudiada fue 70\% de varones y 30\% mujeres, entre 18 y 60 años.

Principales medidas de resultados: Prevalencia de HTLV-I-II en donantes de sangre de Lima.

Resultados: Se obtuvo prevalencias entre 0,64\% (2009) y 1,50\% (2003); el promedio de los 9 años fue 0,97\%. Se incrementó el número de donantes de 2943 el año 2002 a 5824 el 2010. Se halló en 9 años 420 reactivos iniciales por tamización, repetidamente reactivos $(0,93 \%)$ de la población total; siendo la prevalencia nacional $0,83 \%$. Los casos positivos procedieron de los distritos de San Juan de Lurigancho, con $26 \%$.

Conclusiones: Se confirmó prevalencia alta de HTLV-I-II en donantes de sangre en Lima, con cierta endemicidad. La obligatoriedad de tamizaje en los bancos de sangre, en 1997, resultó ser una barrera eficaz en la seguridad transfusional, la misma que debería ser ampliada implementándose procedimientos de desleucocitación en todas las unidades colectadas.

Palabras clave: HTLV I-II, virus linfotrópico humano, donante de sangre.

\section{Evaluación del sistema de información rutinaria de la Estrategia Sanitaria de Prevención VIH/sida en un Hospital III-1}

\author{
Nora Reyes, Zila Caballero, Vilma Béjar, Sofía González, Alberto Laguna, Ninfa Soto
}

Instituto de Medicina Tropical Daniel A. Carrión, Facultad de Medicina, UNMSM

Introducción: La OMS y el sistema de información rutinaria en Salud (PRIMS) proponen la existencia de tres determinantes en los sistemas de información en salud (SIRS): Ios de comportamiento, técnicos, y organizacionales /ambientales, que requieren tener calidad para buen desempeño.

Objetivos: Evaluar el sistema de información en Salud (SIRS) del Programa de ITS/VIH/sida en un hospital nivel III-1 de una zona de alta prevalencia.

Diseño: Estudio descriptivo.

Institución: Instituto de Medicina Tropical Daniel A. Carrión, Facultad de Medicina, UNMSM.

Participantes: Personal de Salud involucrado y una muestra representativa de las dos últimas semanas registros del parte diario e historia clínica de las actividades de la ESNPC ITS-VIH/sida.

Intervenciones: Se usó herramientas estandarizadas para evaluar estos determinantes.

Resultados: Determinantes organizacionales: $60 \%$ percibe promoción del uso de la información, $54 \%$ su uso en la toma de decisiones, $63 \%$ la usó en la resolución de problemas, $52 \%$ señaló que recibe retroalimentación, $53 \%$ que existe apoyo por la gestión. Calidad técnica: 0,26\% omisión de dato; no se encontró inconsistencia de datos en el parte diario; sin embargo, la discordancia entre el parte diario con la Historia clínica fue $52 \%$ en edad y $30 \%$ en diagnóstico. Competencias: la brecha de lo observado con respecto a lo esperado fue $60 \%$ y entre lo autocalificado y lo observado $20 \%$.

Conclusiones: El desempeño del SIRS es débil en sus componentes organizacionales, técnicos y del desempeño, debido a registros manuales y datos repetidos en diferentes formularios. Se necesita capacitación para registro, análisis estadístico y su utilización para la toma de decisiones.

Palabras clave: Sistema de información, ITS, VIH-sida. 